\title{
A roasting method with sugar supplement to make better use of discarded tobacco leaves
}

\author{
Tian-Xiao LI ${ }^{1,2}$ (D), Feng-Cheng SHI ${ }^{1}$, Pin-He LI ${ }^{1}$, Cheng LUO ${ }^{1 *}$, Dong-Liang LI ${ }^{1 *}$
}

\begin{abstract}
Water soluble sugars play an important role in the flavors and irritations of the cigarette sensory quality and the low content of water soluble sugars in the discarded tobacco leaves was a huge obstacle for their application. To make better use of the discarded tobacco leaves, a novel roasting method with sugar supplement was developed to enhance the sugar contents and total flavor compounds (TFCs) of tobaccos. Three main factors in the roasting process namely the reaction time, reaction temperature, and glucose supplement were optimized by single factor methodology. A proper condition was established as reaction time of $10 \mathrm{~min}$, reaction temperature of $140^{\circ} \mathrm{C}$, and glucose supplement of $30 \%$, which was further optimized by the response surface method through a three-level-three-variable Box-Behnken design. Moreover, the flavor compounds of the roasted cut tobacco extracts were analyzed and their effects in cigarettes were also determined. All these results suggested that this simple and easy method could be used to make better use of discarded tobacco leaves.
\end{abstract}

Keywords: discarded tobacco leaves; roasting method; response surface methodology; flavor compounds; caramel reactions.

Practical Application: Cigarette manufacture, discarded tobacco leaves and cigarette caramel flavors.

\section{Introduction}

It is well known that tobacco is an important industrial and economic crop and over 4.2 million tons of tobacco leaves are produced all over the world per year (Zhao et al., 2017). Along with the production of cigarettes, around $25 \%$ of the tobacco leaves are recognized as unqualified and discarded (Zhang et al., 2012; Zhao et al., 2017). Also, some tobacco leaves became useless due to the long-time storage (Zhang et al., 2012). Finally, these tobacco wastes were simply burnt or abandoned, which was not economical and environmentally friendly (Shi et al., 2019). To make better use of the discarded tobacco leaves, several methods such as the extraction of essential oil, nicotine, and tobacco protein were developed for recycle (Guo et al., 2015; Hu et al., 2021; Platis \& Labrou, 2006). However, these methods seem time-consuming and high cost.

Generally in the burning and heating procedures of cigarettes, the water soluble sugars would convert into caramel flavors like furfural and pyranones through the caramel reactions (Hu et al., 2021; Wu et al., 2015;). And high quality flue-cured tobacco leaves contain large amount of soluble sugars and possess proper values of sugar-nicotine ratio. However, the discarded tobacco leaves have relatively low content of soluble sugars, which is the key reason of the weak flavors and strong irritations in the cigarette sensory quality (Zhao et al., 2017). Thus, to make better use of the discarded tobacco leaves, sugar supplement is an important and simple way. Further, a novel and easy roasting method with sugar supplement was developed based on the caramel reactions. The main factors of the roasting process were optimized through single factor and response surface methodologies (Han et al., 2020). Moreover, the flavor compounds of the roasted cut tobacco extracts were analyzed and their effects in the cigarettes were also determined.

\section{Materials and methods}

\subsection{General experimental procedures}

Discarded tobacco leaves (growth origin, Qujing, Yunnan province; year, 2014) were chosen. D-glucose ( $\geq 99.5 \%)$ and D-fructose $(\geq 99.5 \%)$ were purchased from Aladdin Biochemical Technology Co., Ltd. (Shanghai, China). Furfural, 5-HMF (5-hydroxymethylfurfural), and 2-phenylethyl propionate were obtained from Sigma-Aldrich (Alexandria, America). Agilent 1290 HPLC was used for the HPLC-ELSD analysis (Agilent, Santa Clara, USA). Headspace GC-MS and GC-MS analyses were carried out by Agilent 6890GC/5973MS GC-MS (Agilent, Santa Clara, USA), which was equipped with a flame ionization detector. Tobacco leaves were cut using an SY-III tobacco cutting machine (Fubuang, Zhengzhou, China). The cut tobaccos were reacted in an HPX-9082MBE air oven (Boxun, Shanghai, China).

\subsection{Heating procedure}

The tobacco leaves were cut. Then the cut tobaccos $(20.0 \mathrm{~g})$ were blended with glucose and water, which were heated in the air oven at the pre-set temperatures. The roasted tobaccos were taken out immediately at the presupposed time. Afterwards, the 
cut tobaccos $(10.0 \mathrm{~g})$ were extracted with $50 \%$ alcohol under reflux for $40.0 \mathrm{~min}$ and the extracting solution was filtered and supplemented with $50 \%$ alcohol to the weight of $25.0 \mathrm{~g}$.

\subsection{Reaction rate analysis}

D-glucose and D-fructose were dissolved with purified water to a serial of concentrations $(5.00,2.00,1.00,0.50,0.25 \mathrm{mg} / \mathrm{mL})$, which were analyzed by HPLC-ELSD. Through the concentrations and the peak areas, the standard curves were elucidated. Then each of the cut tobaccos and the flue-cured cut tobaccos $(2.0 \mathrm{~g})$ was extracted with $40.0 \mathrm{~g}$ purified water under ultrasonic. The extractions were diluted with water by 10 folds, which were analyzed by HPLC-ELSD.

The Agilent $\mathrm{NH}_{2}$ HPLC column $(250 \mathrm{~mm} \times 4.6 \mathrm{~mm})$ was used and the mobile phase was $75 \%$ acetonitrile (flow rate, $1.0 \mathrm{~mL} / \mathrm{min}$; injection volume, $2.0 \mu \mathrm{L}$ ). HPLC-ELSD was performed on the 385 ELSD detector, which was equipped with $\mathrm{N}_{2}$ as the gas carrier (flow rate, $1.6 \mathrm{~L} / \mathrm{min}$ ). The evaporator temperature was set at $45^{\circ} \mathrm{C}$.

\subsection{GC-MS analysis}

The $50 \%$ alcohol extractions $(15.0 \mathrm{~mL})$ were extracted with $10.0 \mathrm{~mL}$ of $\mathrm{CH}_{2} \mathrm{Cl}_{2}$ twice. The $\mathrm{CH}_{2} \mathrm{Cl}_{2}$ layers were combined and concentrated to $0.9 \mathrm{~mL}$ in the fume hood. Then $0.1 \mathrm{~mL}$ of the internal standard solution (2-phenethyl propionate, $1.78 \mathrm{mg} / \mathrm{mL}$ ) was pipetted to acquire the final volume of $1.0 \mathrm{~mL}$. A DB-5 MS column $(60 \mathrm{~m} \times 0.25 \mathrm{~mm}$ i.d. $\times 0.25 \mu \mathrm{m}$ d.f. $)$ was chosen for the GC-MS analysis (injection volume, $1.0 \mu \mathrm{L}$ ). The column temperature was optimized as following: $50^{\circ} \mathrm{C}$, hold for $2 \mathrm{~min}$; $50^{\circ} \mathrm{C}$ to $120^{\circ} \mathrm{C}, 6^{\circ} \mathrm{C} / \mathrm{min} ; 120^{\circ} \mathrm{C}$ to $240^{\circ} \mathrm{C}, 12^{\circ} \mathrm{C} / \mathrm{min}$, hold for $5 \mathrm{~min} ; 240^{\circ} \mathrm{C}$ to $280^{\circ} \mathrm{C}, 15^{\circ} \mathrm{C} / \mathrm{min}$, hold for $3 \mathrm{~min}$. Finally, the GC-MS TICs (total ion chromatograms) were obtained and the flavor compounds were determined by searching in the NIST 17 database. The concentrations of flavor compounds were calculated through the internal standard method.

\subsection{Optimization of glucose supplement}

The cut tobaccos $(20.0 \mathrm{~g})$ were blended with $0.0,2.0,4.0$, 6.0 , and $8.0 \mathrm{~g}$ of glucose and $4.0 \mathrm{~g}$ of water respectively. They were heated in the air oven at $140^{\circ} \mathrm{C}$ for 10 minutes. Then the reaction rates and total flavor compounds (TFCs) of the cut tobaccos were determined by HPLC-ELSD and GC-MS.

\subsection{Optimization of reaction temperature}

The cut tobaccos $(20.0 \mathrm{~g}$ ) were blended with $6.0 \mathrm{~g}$ of glucose and $4.0 \mathrm{~g}$ of water. Then they were heated in the air oven at $130^{\circ} \mathrm{C}, 140{ }^{\circ} \mathrm{C}, 150^{\circ} \mathrm{C}$, and $160^{\circ} \mathrm{C}$ for 10 minutes respectively. The reaction rates and TFCs were determined as aforementioned.

\subsection{Optimization of reaction time}

The cut tobaccos $(20.0 \mathrm{~g})$ were blended with $6.0 \mathrm{~g}$ of glucose and $4.0 \mathrm{~g}$ of water. Then they were heated in the air oven at $140{ }^{\circ} \mathrm{C}$ for 5,10 , and 15 minutes respectively. The reaction rates and TFCs were determined as above-mentioned.

\subsection{Response surface optimization and statistical analysis}

Based on the above single-factor test, the response surface method was performed to study the effects of reaction time (min, $A$ ), reaction temperature $\left({ }^{\circ} \mathrm{C}, B\right)$, and glucose supplement $(100 \%$, $C$ ) on the TFCs of cut tobaccos. A three-level-three-variable Box-Behnken design (BBD) was carried out through the software Design-Expert 10.0.7 (State-Ease, Inc., Minneapolis, USA). The experimental factors and levels were chosen according to Table 1 and a total of 17 combination experiments was conducted. The experimental data were collected and analyzed by multiple regressions. The model was regarded as significant when the values of $p$ were less than 0.05 . In addition, the significance of the regression coefficients was verified by ANOVA (analysis of variance) through the F-test with probability $(p)$ value $<0.05$.

\subsection{Headspace GC-MS analysis}

Each of the formula cut tobaccos $(5.0 \mathrm{~g})$ was added with the extractions ( $5.0 \mathrm{mg}, 0.1 \% ; 15.0 \mathrm{mg}, 0.3 \%$ ), which was kept hermetically for $48 \mathrm{~h}$. The control group was supplemented with $50 \%$ alcohol. Then the cut tobaccos were transferred into the headspace bottles, which were analyzed by headspace GC-MS (Luckovitch \& Pagliano, 2019). The headspace incubation was performed at $90^{\circ} \mathrm{C}$ for 10 minutes. A HP-ULTRA 2 MS column $(50 \mathrm{~m} \times 0.32 \mathrm{~mm}$ i.d. $\times 0.25 \mu \mathrm{m}$ d.f. $)$ was chosen for the GC-MS analysis (injection volume, $2000.0 \mu \mathrm{L}$ ). The column temperature method was: $40^{\circ} \mathrm{C}$, hold for $3 \mathrm{~min} ; 40^{\circ} \mathrm{C}$ to $200{ }^{\circ} \mathrm{C}, 5^{\circ} \mathrm{C} / \mathrm{min}$, hold for $5 \mathrm{~min} ; 200^{\circ} \mathrm{C}$ to $230^{\circ} \mathrm{C}, 10^{\circ} \mathrm{C} / \mathrm{min}$, hold for $1 \mathrm{~min}$. The GC-MS TICs were analyzed by the Agilent GC-MS Chemical Station through the NIST 17 database.

\section{Results and discussion}

\subsection{Standard curves of glucose and fructose}

According to the concentrations and the peak areas (Table 2), the standard curves (Figure 1) were established as $y=1137.2 x+52.8$ (glucose) and $y=1907.9 x-89.2$ (fructose). Their $\mathrm{R}^{2}$ values were revealed as 0.9995 and 0.9999 respectively, which suggested the linearity of the standard curves was nice (Li et al., 2020).

Table 1. Selected factors and their levels in the BBD.

\begin{tabular}{ccccc}
\hline \multirow{2}{*}{ symbol } & \multirow{2}{*}{ factors } & \multicolumn{3}{c}{ factor levels } \\
\cline { 3 - 5 } & & -1 & 0 & 1 \\
\hline$A$ & reaction time $(\min )$ & 5 & 10 & 15 \\
$B$ & reaction temperature $\left({ }^{\circ} \mathrm{C}\right)$ & 130 & 140 & 150 \\
$C$ & glucose supplement $(100 \%)$ & 20 & 30 & 40 \\
\hline
\end{tabular}

Table 2. The HPLC-ELSD peak areas of different glucose and fructose solutions.

\begin{tabular}{ccc}
\hline concentrations $(\mathrm{mg} / \mathrm{mL})$ & glucose & fructose \\
\hline 0.25 & 296.1 & 440.9 \\
0.50 & 618.7 & 820.2 \\
1.00 & 1273.5 & 1838.4 \\
2.00 & 2284.4 & 3707.6 \\
5.00 & 5741.2 & 9463.6 \\
\hline
\end{tabular}




\subsection{Optimization of glucose supplement}

The cut tobaccos $(20.0 \mathrm{~g})$ were blended with $0.0(0 \%), 2.0$ (10\%), 4.0 (20\%), 6.0 (30\%), and $8.0(40 \%) \mathrm{g}$ of glucose and $4.0 \mathrm{~g}$ of water, which were heated at $140{ }^{\circ} \mathrm{C}$ for 10 minutes. Then the TFCs and reaction rates of the cut tobaccos were determined by GC-MS and HPLC-ELSD (Table 3).

Through the peak areas and standard curves, the water soluble sugar (mainly glucose and fructose) contents of the cut tobacco control were calculated as $4.9 \%$ for glucose and $8.0 \%$ for fructose, respectively. Along with the glucose supplement, the reaction rates of two monosaccharides were firstly increased and subsequently decreased, so were the contents of TFCs (Figure 2).
And the highest values of reaction rate and TFC content were found at the glucose supplement of $30 \%$.

\subsection{Optimization of reaction temperature}

Each of the cut tobaccos $(20.0 \mathrm{~g})$ was blended with $6.0 \mathrm{~g}$ of glucose and $4.0 \mathrm{~g}$ of water and they were heated at $130^{\circ} \mathrm{C}$, $140{ }^{\circ} \mathrm{C}, 150{ }^{\circ} \mathrm{C}$, and $160^{\circ} \mathrm{C}$ for 10 minutes, respectively. The reaction rates and TFCs were determined as shown in Table 4 (Li et al., 2014). It was interesting to note that the reaction rates of two monosaccharides were enhanced along with the reaction temperature increase. However, the contents of TFCs were firstly increased and subsequently decreased, possibly due to the flavor compound loss at excessively high temperature. Thus, the suitable reaction temperature was proposed at $140{ }^{\circ} \mathrm{C}$.

Table 3. The TFCs and reaction rates with different glucose supplement.

\begin{tabular}{|c|c|c|c|c|c|c|c|}
\hline \multirow{2}{*}{$\begin{array}{c}\text { glucose } \\
\text { supplement }\end{array}$} & \multirow[b]{2}{*}{ TFCs $(\mu \mathrm{g} / \mathrm{mL})$} & \multicolumn{3}{|c|}{ glucose } & \multicolumn{3}{|c|}{ fructose } \\
\hline & & $\begin{array}{c}\text { peak area of } \\
\text { control }\end{array}$ & $\begin{array}{c}\text { peak area of } \\
\text { reaction }\end{array}$ & reaction rate $(\%)$ & $\begin{array}{c}\text { peak area of } \\
\text { control }\end{array}$ & $\begin{array}{c}\text { peak area of } \\
\text { reaction }\end{array}$ & reaction rate $(\%)$ \\
\hline $0 \%$ & $258.2 \pm 3.2$ & 610.4 & $560.2 \pm 13.4$ & $8.2 \pm 2.2$ & 1552.6 & $1438.4 \pm 26.4$ & $7.4 \pm 1.7$ \\
\hline $10 \%$ & $265.8 \pm 4.5$ & 1742.2 & $1575.0 \pm 29.6$ & $9.6 \pm 1.7$ & 1523.9 & $1384.1 \pm 32.0$ & $9.2 \pm 2.1$ \\
\hline $20 \%$ & $294.2 \pm 11.6$ & 2636.5 & $2226.5 \pm 81.7$ & $15.6 \pm 3.1$ & 1622.9 & $1336.7 \pm 45.4$ & $17.6 \pm 2.8$ \\
\hline $30 \%$ & $365.5 \pm 7.9$ & 4215.5 & $3498.2 \pm 118.0$ & $17.0 \pm 2.8$ & 1579.8 & $1261.9 \pm 39.5$ & $20.1 \pm 2.5$ \\
\hline $40 \%$ & $346.1 \pm 4.8$ & 4640.6 & $4104.7 \pm 106.7$ & $11.5 \pm 2.3$ & 1650.0 & $1335.5 \pm 49.5$ & $19.1 \pm 3.0$ \\
\hline
\end{tabular}
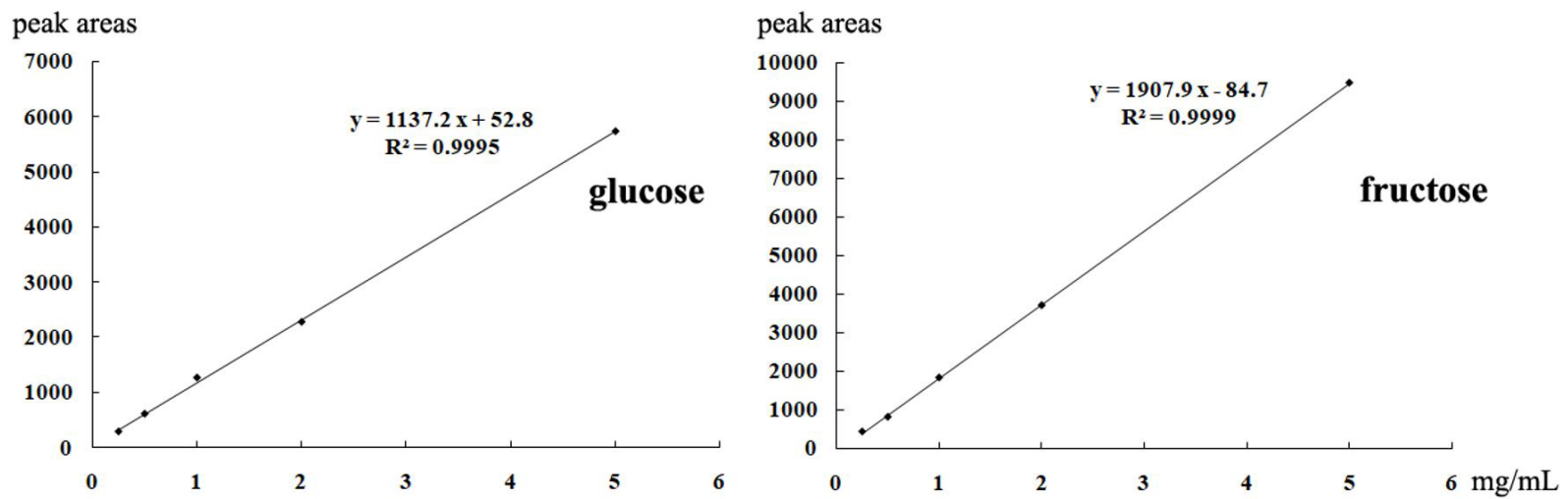

Figure 1. HPLC-ELSD standard curves of glucose and fructose.
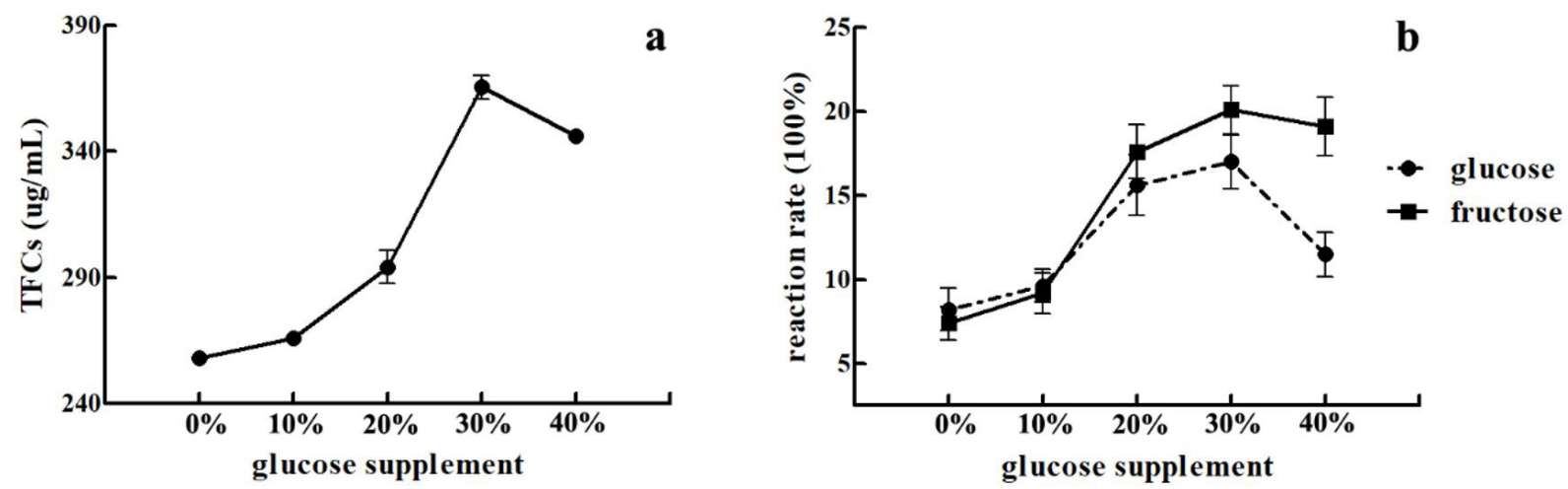

Figure 2. TFCs (a) and reaction rates (b) with different glucose supplement. 


\subsection{Optimization of reaction time}

The cut tobaccos $(20.0 \mathrm{~g})$ were blended with $6.0 \mathrm{~g}$ of glucose and $4.0 \mathrm{~g}$ of water and they were heated in the air oven at $140{ }^{\circ} \mathrm{C}$ for 5, 10, and 15 minutes, respectively. The reaction rates and TFCs were determined as shown in Table 5. Along with the reaction time increase, the reaction rates of two monosaccharides were enhanced, but the contents of TFCs were firstly increased and subsequently decreased. The proper reaction time was suggested at 10 minutes.

\subsection{GC-MS analysis}

The cut tobaccos were blended with $30 \%$ of glucose and roasted at $140{ }^{\circ} \mathrm{C}$ for 10 minutes. The control group was the cut tobaccos that blended with $30 \%$ of glucose but not being heated. Then the cut tobaccos were extracted and the flavor compounds were analyzed by GC-MS. As shown in Table 6, the contents of empyreumatique and sweet flavor compounds were obviously increased after being roasted at $140{ }^{\circ} \mathrm{C}$ for 10 minutes, such as 5-HMF, 5,6-dihydroxy- $2 H$-pyran-2one, 2,3-dihydro-3,5-dihydroxy-6-methyl-4H-pyran-4-one (DDMP), maltol, and 3,5-dihydroxy-2-methyl-4H-pyran4-one (Li et al., 2020). Noteworthily, the contents of 5-HMF and DDMP were enhanced by 1.4 and 2.2 folds, respectively. Moreover, the concentrations of the fatty acid and their esters including of $(Z, Z, Z)-9,12,15$-octadecatrienoic acid, $(Z, Z)-9,12$ octadecadienoic acid, $(Z, Z, Z)-9,12,15$-octadecatrienoic acid methyl ester, (Z,Z)-9,12-octadecadienoic acid methyl ester were also increased, which could provide oil and sweet flavors. The same phenomena could also be observed for the tobacco terpene flavors like 8-methyl-5-(1-methylethyl)-(E)-6,8-nonadien-2-one, megastigmatrienone, 6-isopropenyl-4,8a-dimethyl-4a,5,6,7,8,8ahexahydro-1H-naphthalen-2-one, and 1,5,9-trimethyl-12(1-methylethyl)-4,8,13-cyclotetradecatriene-1,3-diol.

It could be concluded that through the roasting method with glucose supplement, the aroma compounds were obviously increased, which could be associated with the caramel reactions of sugars and the degradation reactions of tobacco macromolecule flavor precursors.

\subsection{Response surface optimization of the roasting method}

The roasting process was further optimized by three-levelthree-variable BBD (Table 1), using TFCs as the response values (Fan et al., 2020; Zoubi et al., 2021). Three factors were studied namely reaction time $(\mathrm{min}, A)$, reaction temperature $\left({ }^{\circ} \mathrm{C}, B\right)$, and glucose supplement $(100 \%, C)$. A total of 17 combination experiments was conducted according to the design and the results were shown in Table 7.

Careful analysis of the ANOVA results (Table 8) suggested that the model was extremely statistical significant according to the F-values (34.11) and $p$-values $(<0.0001)$. The value of "lack of fit $p$-value" was 0.1326 , which indicated that the "lack of fit" was not significant. Also, the correlation coefficient $\left(\mathrm{R}^{2}\right)$ value was 0.9777 . Thus, the model exhibited nice reasonability and feasibility and the predicted values were in accordance with the measured data.

The polynomial equation of TFCs was established as $\mathrm{Y}=365.50+5.40 \times A+15.22 \times B+16.87 \times C-9.66 \times A B+6.33 \times A C$ $+3.83 \times B C-32.44 \times A^{2}-43.99 \times B^{2}-36.23 \times C^{2}$. The factors reaction temperature $(B, p=0.0021)$ and glucose supplement $(C$, $p=0.0012$ ) were statistically significant, while the effects of three factors on the production of TFCs were $C>B>>A$. In addition, the model items $\mathrm{A}^{2}, \mathrm{~B}^{2}$, and $\mathrm{C}^{2}$ were also extremely significant.

Figure 3 described the three-dimensional response surfaces of the three factor interactions. The surfaces were hemisphere shape with tops. According to the BBD, the maximal TFC was achieved with the optimal factor values of $10.408 \mathrm{~min}, 141.748^{\circ} \mathrm{C}$, and $34.292 \%$. The experiment under this condition with slight changes (10.4 $\mathrm{min}, 141.8{ }^{\circ} \mathrm{C}$, and $34.3 \%$ ) was performed, which gave a TFC value of $370.06 \mu \mathrm{g} / \mathrm{mL}$. This result was not significantly different from the predicted value $(369.15 \mu \mathrm{g} / \mathrm{mL})$. Thus, the regression model could effectively predict the optimal conditions of this roasting process.

Table 4. The TFCs and reaction rates at different reaction temperature.

\begin{tabular}{|c|c|c|c|c|c|c|c|}
\hline \multirow[b]{2}{*}{ temp. } & \multirow[b]{2}{*}{ TFCs $(\mu \mathrm{g} / \mathrm{mL})$} & \multicolumn{3}{|c|}{ glucose } & \multicolumn{3}{|c|}{ fructose } \\
\hline & & $\begin{array}{c}\text { peak area of } \\
\text { control }\end{array}$ & $\begin{array}{l}\text { peak area of } \\
\text { reaction }\end{array}$ & reaction rate $(\%)$ & $\begin{array}{c}\text { peak area of } \\
\text { control }\end{array}$ & $\begin{array}{c}\text { peak area of } \\
\text { reaction }\end{array}$ & reaction rate $(\%)$ \\
\hline $130^{\circ} \mathrm{C}$ & $278.2 \pm 5.7$ & 4215.5 & $3516.0 \pm 75.9$ & $16.6 \pm 1.8$ & 1579.8 & $1287.7 \pm 34.8$ & $18.5 \pm 1.9$ \\
\hline $140^{\circ} \mathrm{C}$ & $365.5 \pm 7.9$ & 4215.5 & $3498.2 \pm 118.0$ & $17.0 \pm 2.8$ & 1579.8 & $1261.9 \pm 39.5$ & $20.1 \pm 2.5$ \\
\hline $150^{\circ} \mathrm{C}$ & $319.9 \pm 9.2$ & 4215.5 & $3226.9 \pm 130.7$ & $23.5 \pm 3.1$ & 1579.8 & $1220.6 \pm 37.9$ & $22.7 \pm 2.4$ \\
\hline $160^{\circ} \mathrm{C}$ & $291.8 \pm 3.2$ & 4215.5 & $3131.3 \pm 101.2$ & $25.7 \pm 2.4$ & 1579.8 & $1170.5 \pm 42.7$ & $25.9 \pm 2.7$ \\
\hline
\end{tabular}

Table 5. The TFCs and reaction rates at different reaction time.

\begin{tabular}{|c|c|c|c|c|c|c|c|}
\hline \multirow{2}{*}{$\begin{array}{l}\text { reaction time } \\
(\min )\end{array}$} & \multirow[b]{2}{*}{ TFCs $(\mu \mathrm{g} / \mathrm{mL})$} & \multicolumn{3}{|c|}{ glucose } & \multicolumn{3}{|c|}{ fructose } \\
\hline & & $\begin{array}{c}\text { peak area of } \\
\text { control }\end{array}$ & $\begin{array}{l}\text { peak area of } \\
\text { reaction }\end{array}$ & $\begin{array}{c}\text { reaction rate } \\
(\%)\end{array}$ & $\begin{array}{c}\text { peak area of } \\
\text { control }\end{array}$ & $\begin{array}{l}\text { peak area of } \\
\text { reaction }\end{array}$ & $\begin{array}{c}\text { reaction rate } \\
(\%)\end{array}$ \\
\hline 5 & $292.7 \pm 4.2$ & 4215.5 & $3616.9 \pm 67.4$ & $14.2 \pm 1.6$ & 1579.8 & $1406.0 \pm 28.4$ & $15.1 \pm 1.8$ \\
\hline 10 & $365.5 \pm 6.9$ & 4215.5 & $3498.2 \pm 118.0$ & $17.0 \pm 2.8$ & 1579.8 & $1261.9 \pm 39.5$ & $20.1 \pm 2.5$ \\
\hline 15 & $326.8 \pm 5.8$ & 4215.5 & $3186.9 \pm 80.1$ & $24.4 \pm 1.9$ & 1579.8 & $1164.3 \pm 33.2$ & $26.3 \pm 2.1$ \\
\hline
\end{tabular}


Table 6. GC-MS analysis of roasted cut tobaccos with glucose supplement $(\mu \mathrm{g} / \mathrm{mL})$.

\begin{tabular}{|c|c|c|c|}
\hline$t_{\mathrm{R}}(\min )$ & flavor compounds & control & roasted \\
\hline 6.61 & 1,1-diethoxy-ethane & 3.08 & 3.14 \\
\hline 9.61 & butyrolactone & 0.16 & - \\
\hline 11.80 & benzyl alcohol & 0.47 & 0.33 \\
\hline 11.91 & pantolactone & 0.42 & 0.27 \\
\hline 12.27 & 1-(1H-pyrrol-2-yl)-ethanone & 0.81 & 0.77 \\
\hline 13.24 & maltol & 0.27 & 0.33 \\
\hline 13.33 & phenylethyl alcohol & 0.50 & 0.18 \\
\hline 13.90 & 2,3-dihydro-3,5-dihydroxy-6-methyl-4H-pyran-4-one & 1.23 & 3.95 \\
\hline 13.94 & benzoic acid & 0.32 & 0.44 \\
\hline 14.27 & 5,6-dihydroxy-2H-pyran-2-one & $-{ }^{\mathrm{a}}$ & 1.39 \\
\hline 14.58 & 3,5-dihydroxy-2-methyl-4H-pyran-4-one & 0.25 & 0.65 \\
\hline 14.65 & 5-hydroxymethyldihydrofuran-2-one & - & 0.32 \\
\hline 15.29 & 5-hydroxymethylfurfural & 0.63 & 1.54 \\
\hline 15.62 & benzeneacetic acid & 1.62 & 2.18 \\
\hline 18.06 & 8-methyl-5-(1-methylethyl)-(E)-6,8-nonadien-2-one & 1.67 & 2.15 \\
\hline 18.17 & nicotine & 34.60 & 42.05 \\
\hline 19.41 & 4-hydroxy-benzeneethanol & 0.59 & 0.69 \\
\hline 19.77 & 3-(3,4-dihydro-2H-pyrrol-5-yl)-pyridine & - & 0.30 \\
\hline 21.99 & 5,6,7,7a-tetrahydro-4,4,7a-trimethyl-2(4H)-benzofuranone & 3.85 & 4.60 \\
\hline 22.67 & megastigmatrienone & 2.06 & 2.14 \\
\hline 23.22 & 3-hydroxy- $\beta$-damascone & 2.57 & 4.49 \\
\hline 23.59 & tabanone & 2.42 & 2.84 \\
\hline 23.84 & 4-(3-hydroxy-1-butenyl)-3,5,5-trimethyl-2-cyclohexen-1-one & 6.50 & 7.70 \\
\hline 24.15 & 2,6-diaminopurine & 4.42 & 5.81 \\
\hline 24.98 & 4-(3-hydroxybutyl)-3,5,5-trimethyl-2-cyclohexen-1-one & 3.42 & 4.43 \\
\hline 25.11 & cotinine & 1.95 & 2.73 \\
\hline 25.55 & 4-((1E)-3-hydroxy-1-propenyl)-2-methoxyphenol & 1.46 & 2.13 \\
\hline 25.63 & tetradecanoic acid & - & 0.58 \\
\hline 26.46 & 4-hydroxy-3,5,5-trimethyl-4-(3-oxo-1-butenyl)-2-cyclohexen-1-one & 0.78 & 1.18 \\
\hline 26.93 & indole-5-aldehyde & 0.47 & 0.61 \\
\hline 27.24 & aromandendrene & 2.02 & 4.15 \\
\hline 27.32 & rishitin & 2.49 & 3.16 \\
\hline 28.61 & hexadecanoic acid methyl ester & 2.47 & 3.26 \\
\hline 28.74 & solavetivone & 0.82 & 4.14 \\
\hline 29.08 & 6-isopropenyl-4,8a-dimethyl-4a,5,6,7,8,8a-hexahydro- $1 H$-naphthalen-2-one & 0.93 & 2.68 \\
\hline 29.21 & n-hexadecanoic acid & 15.75 & 26.77 \\
\hline 29.70 & scopoletin & 38.19 & 47.43 \\
\hline 31.85 & bisabolene epoxide & 9.36 & 15.91 \\
\hline 32.07 & $(Z, Z)$-9,12-octadecadienoic acid methyl ester & 2.11 & 2.79 \\
\hline 32.20 & $(Z, Z, Z)-9,12,15$-octadecatrienoic acid methyl ester & 7.53 & 5.95 \\
\hline 32.83 & 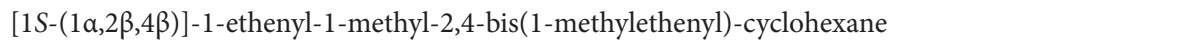 & 6.81 & 9.08 \\
\hline 32.92 & $(Z, Z)-9,12$-octadecadienoic acid & 4.77 & 8.97 \\
\hline 33.10 & $(Z, Z, Z)-9,12,15$-octadecatrienoic acid & 20.91 & 35.27 \\
\hline 33.62 & 1,5,9-trimethyl-12-(1-propyl)-4,8,13-cyclotetradecatriene-1,3-diol & 5.00 & 8.99 \\
\hline 34.77 & 4-(5,5-dimethyl-1-oxaspiro[2.5]oct-4-yl)-3-buten-2-one & 13.89 & 19.04 \\
\hline 34.96 & 1,1a,5,6,7,8-hexahydro-4a,8,8-trimethyl-[1aR-(1aa,4a $\beta, 8 \mathrm{a} S)]$-cyclopropa[d]naphthalen-2(4aH)-one & 8.86 & 10.82 \\
\hline 35.25 & thunbergol & 17.20 & 20.28 \\
\hline 36.39 & 1,5,9-trimethyl-12-(1-methylethyl)-4,8,13-cyclotetradecatriene-1,3-diol & 18.87 & 22.90 \\
\hline 39.93 & (Z)-9-octadecenamide & - & 7.00 \\
\hline \multirow[t]{2}{*}{40.15} & 1-(4-tert-butylphenyl)propan-2-one & - & 5.11 \\
\hline & total & 254.3 & 365.5 \\
\hline
\end{tabular}

anot detected. 
Table 7. TFCs of different experiments generated by the BBD.

\begin{tabular}{ccccc}
\hline No. & reaction time $(\mathrm{min})$ & reaction temperature $\left({ }^{\circ} \mathrm{C}\right)$ & glucose supplement $(100 \%)$ & TICs $(\mu \mathrm{g} / \mathrm{mL})$ \\
\hline 1 & $5(-1)$ & $150.0(1)$ & $30.0(0)$ & 317.19 \\
2 & $5(-1)$ & $130.0(-1)$ & $30.0(0)$ & 264.12 \\
3 & $5(-1)$ & $140.0(0)$ & $40.0(1)$ & 294.78 \\
4 & $5(-1)$ & $140.0(0)$ & $20.0(-1)$ & 274.12 \\
5 & $15(1)$ & $130.0(-1)$ & $30.0(0)$ & 280.26 \\
6 & $15(1)$ & $140.0(0)$ & $20.0(-1)$ & 286.22 \\
7 & $15(1)$ & $150.0(1)$ & $30.0(0)$ & 294.70 \\
8 & $15(1)$ & $140.0(0)$ & $40.0(1)$ & 332.19 \\
9 & $10(0)$ & $150.0(1)$ & $20.0(-1)$ & 277.91 \\
10 & $10(0)$ & $130.0(-1)$ & $20.0(-1)$ & 258.47 \\
11 & $10(0)$ & $130.0(-1)$ & $40.0(1)$ & 284.97 \\
12 & $10(0)$ & $150.0(1)$ & $30.0(1)$ & $30.0(0)$ \\
13 & $10(0)$ & $140.0(0)$ & $30.0(0)$ & 372.75 \\
15 & $10(0)$ & $140.0(0)$ & $30.0(0)$ & 367.59 \\
16 & $10(0)$ & $140.0(0)$ & $30.0(0)$ & 359.44 \\
17 & $10(0)$ & $140.0(0)$ & $30.0(0)$ & 358.24 \\
\end{tabular}

Table 8. ANOVA for the response surface quadratic model.

\begin{tabular}{|c|c|c|c|c|c|}
\hline source & sum of squares & degree of freedom & mean square & F value & $p$-value $($ prob $>\mathrm{F})$ \\
\hline model & 25144.31 & 9 & 2793.81 & 34.11 & $<0.0001$ \\
\hline$A$ & 232.94 & 1 & 232.94 & 2.84 & 0.1356 \\
\hline$B$ & 1852.45 & 1 & 1852.45 & 22.62 & 0.0021 \\
\hline C & 2277.33 & 1 & 2277.33 & 27.81 & 0.0012 \\
\hline$A B$ & 373.03 & 1 & 373.03 & 4.55 & 0.0702 \\
\hline$A C$ & 160.21 & 1 & 160.21 & 1.96 & 0.2046 \\
\hline$B C$ & 58.77 & 1 & 58.77 & 0.72 & 0.4250 \\
\hline$A^{2}$ & 4431.17 & 1 & 4431.17 & 54.10 & 0.0002 \\
\hline$B^{2}$ & 8149.13 & 1 & 8149.13 & 99.50 & $<0.0001$ \\
\hline$C^{2}$ & 5527.87 & 1 & 5527.87 & 67.50 & $<0.0001$ \\
\hline residual & 573.30 & 7 & 81.90 & & \\
\hline lack of fit & 412.69 & 3 & 137.56 & 3.43 & 0.1326 \\
\hline pure error & 160.61 & 4 & 40.15 & & \\
\hline
\end{tabular}
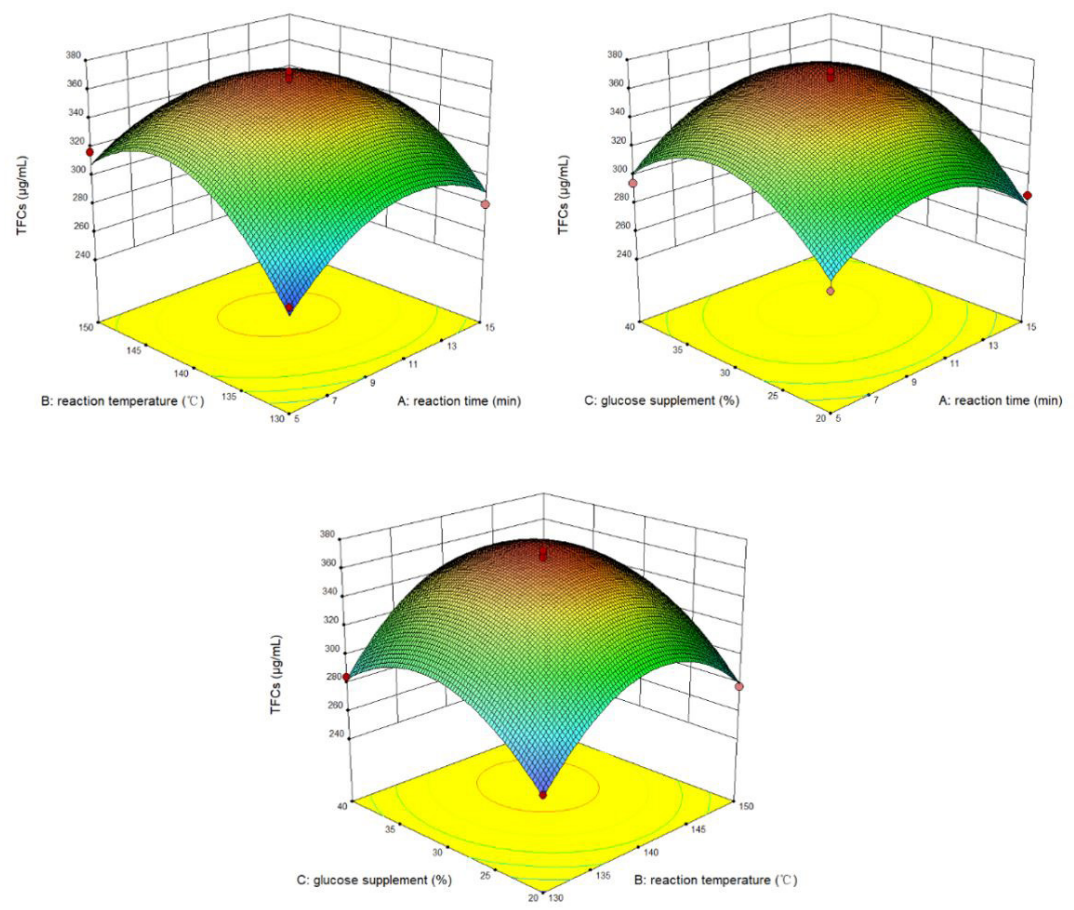

Figure 3. Response surfaces of three factors on the yield of TFCs. 
Table 9. Headspace GC-MS peak areas of roasted cut tobacco extractions.

\begin{tabular}{|c|c|c|c|c|}
\hline$t_{\mathrm{R}}(\min )$ & flavor compounds & control & $0.1 \%$ addition & $0.3 \%$ addition \\
\hline 4.87 & acetic acid & 61475688 & 85685786 & 173672684 \\
\hline 5.75 & 3-methyl-butanal & 5924859 & 6616821 & 6830919 \\
\hline 6.00 & 2-methyl-butanal & $-^{\mathrm{a}}$ & 2857983 & 3178841 \\
\hline 8.37 & propylene glycol & 320729151 & 396867266 & 539077840 \\
\hline 9.64 & 2,3-butanediol & 3454541 & 5013575 & 5960757 \\
\hline 11.43 & furfural & 2041991 & 2298626 & 2380719 \\
\hline 16.05 & benzaldehyde & 950241 & 903362 & 922509 \\
\hline 16.85 & 6-methyl-5-hepten-2-one & 1271307 & 1400174 & 1670814 \\
\hline 18.41 & D-limonene & 2646435 & 2965837 & 3746077 \\
\hline 18.90 & benzeneacetaldehyde & 2734702 & 2972817 & 4092086 \\
\hline 27.79 & 1,3-diacetin & 64341166 & 89736611 & 105252709 \\
\hline 28.25 & nicotine & 182551363 & 207481252 & 226379717 \\
\hline 33.23 & $\begin{array}{c}\text { 5,6,7,7a-tetrahydro-4,4,7a-trimethyl-2(4H)- } \\
\text { benzofuranone }\end{array}$ & 841516 & 1264526 & 1424312 \\
\hline 34.40 & 2,2,4-trimethyl-1,3-pentanediol diisobutyrate & 11935857 & 14070347 & 14551317 \\
\hline 40.97 & neophytadiene & 23119649 & 25585054 & 28874708 \\
\hline
\end{tabular}

${ }^{a}$ not detected.
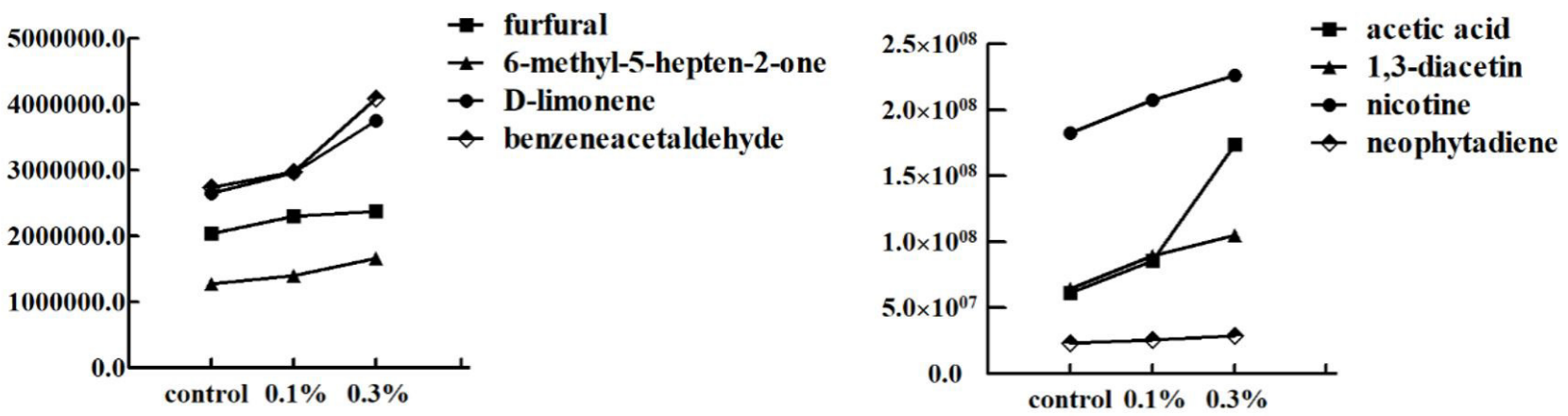

Figure 4. The contents of flavor compounds determined by headspace GC-MS.

\subsection{Headspace GC-MS analysis}

As shown in Table 9 and Figure 4, after the addition of roasted tobacco extractions, the contents of furfural, benzeneacetaldehyde, 6-methyl-5-hepten-2-one, and D-limonene were all increased, which could bring caramel, apricot kernel, and fruit flavors for the cigarettes (Raber et al., 2021). Moreover, the significant increase of 5,6,7,7a-tetrahydro-4,4,7a-trimethyl-2(4H)-benzofuranone, neophytadiene, and acetic acid could enhance the flavor richness and reduce irritations in the cigarettes. Thus, the roasted cut tobacco extracts could be used in cigarettes.

\section{Conclusions}

A novel and easy roasting method with sugar supplement was developed to make better use of the discarded tobacco leaves. Three main factors namely the reaction time, reaction temperature, and glucose supplement in the roasting process were optimized through single factor and response surface methodologies. The perfumed compounds of the roasted cut tobacco extracts were more rich, which could enhance the flavors and tastes of cigarettes. All these results suggested that this method could be promisingly used in the tobacco industry with further development.

\section{Acknowledgments}

This research work was funded by the Technical Program of China Tobacco Sichuan Industrial Co., Ltd. [hx201908] and the Key Scientific Research Projects of Higher Education Institutions of Henan Province [20A350020].

\section{References}

Fan, S., Yang, G., Zhang, J., Li, J., \& Bai, B. (2020). Optimization of ultrasound-assisted extraction using response surface methodology for simultaneous quantitation of six flavonoids inflos sophorae immaturus and antioxidant activity. Molecules, 25(8), 1767. http:// dx.doi.org/10.3390/molecules25081767. PMid:32290627.

Guo, H., Li, F., Wang, S., Li, S., Xiao, W., \& Liu, W. (2015). Enhanced protein extraction from tobacco roots for proteomic analysis. 
Analytical Letters, 48(1), 16-24. http://dx.doi.org/10.1080/00032 719.2014.930871.

Han, L., Han, Q., Yang, Y., Wang, H., Wang, S. L., \& Li, G. (2020). Characterization and biological activities of seed oil extracted from Berberis dasystachya Maxim. by the supercritical carbon dioxide extraction method. Molecules, 25(8), 1836. http://dx.doi.org/10.3390/ molecules25081836. PMid:32316267.

Hu, B., Gu, K., Gong, J., Zhang, K., Chen, D., He, X., Chen, Y., Gao, K., Jin, Y., Huang, K., Zhu, Y., \& Zou, C. (2021). The effect of fluecuring procedure on the dynamic change of microbial diversity of tobaccos. Scientific Reports, 11(1), 5354. http://dx.doi.org/10.1038/ s41598-021-84875-6. PMid:33686144.

Li, P., Wu, M., \& Xie, J. (2014). Changes in levels of amino acids and basic components in Burley tobacco produced by roasting. Btrge Zur Tabakforschung International, 20(7), 459-466.

Li, T. X., Ji, L. B., Jiang, Z. R., Geng, Z. Z., Shentu, H. Q., Liu, M. C., Xie, Y. F., Hu, J., Liu, Y. F., \& Li, D. L. (2020). Caramel products of glucose with water during heating process and their bioactivities. International Journal of Food Properties, 23(1), 971-985. http:// dx.doi.org/10.1080/10942912.2020.1770788.

Luckovitch, N., \& Pagliano, E. (2019). A reference isotope dilution headspace GC/MS method for the determination of nitrite and nitrate in meat samples. International Journal of Food Science \& Technology, 55(3), 1110-1118. http://dx.doi.org/10.1111/ijfs.14438.

Platis, D., \& Labrou, N. E. (2006). Development of an aqueous twophase partitioning system for fractionating therapeutic proteins from tobacco extract. Journal of Chromatography A, 1128(1-2), 114-124. http://dx.doi.org/10.1016/j.chroma.2006.06.047. PMid:16828788.
Raber, A. G., Peachey-Stoner, R. J., Cessna, S. G., \& Siderhurst, M. S. (2021). Headspace GC-MS analysis of differences in intra- and interspecific terpene profiles of Picea pungens Engelm. and P. abies (L.) Karst. Phytochemistry, 181, 112541. http://dx.doi.org/10.1016/j. phytochem.2020.112541. PMid:33099223.

Shi, W., Li, H., Zeng, X., Zhang, H., \& Qin, X. (2019). The extraction of tobacco protein from discarded tobacco leaf by hollow fiber membrane integrated process. Innovative Food Science \& Emerging Technologies, 58, 102245. http://dx.doi.org/10.1016/j.ifset.2019.102245.

Wu, Y., Liao, T., Wang, M., Zhang, W., \& Zhu, B. (2015). Development and application of consumer experience sensory evaluation method for Chinese-style cigarette. Tobacco Science and Technology, 48(5), 80-84.

Zhang, X., Gao, H., Zhang, L., Liu, D., \& Ye, X. (2012). Extraction of essential oil from discarded tobacco leaves by solvent extraction and steam distillation, and identification of its chemical composition. Industrial Crops and Products, 39, 162-169. http://dx.doi.org/10.1016/j. indcrop.2012.02.029.

Zhao, G. H., Yu, Y. L., Zhou, X. T., Lu, B. Y., Li, Z. M., \& Feng, Y. J. (2017). Effects of drying pretreatment and particle size adjustment on the composting process of discarded flue-cured tobacco leaves. Waste Management \& Research, 35(5), 534-540. http://dx.doi. org/10.1177/0734242X17690448. PMid:28190373.

Zoubi, Y. E., Fadil, M., Dalila, B., Lalami, A. E. O., \& Farah, A. (2021). Ultrasound-assisted extraction of phenolic compounds from Moroccan Lavandula stoechas L.: optimization using response surface methodology. Journal of Chemistry, 2021, 8830902. 